\title{
A FOURTH GRADE EXPERIENCE
}

\author{
DONALD G. SAARI \\ Northwestern University, Departments of Mathematics and of Economics
}

August, 1991

"We've been trying to tell you you're wrong!" With this severe reprimand, a fourthgrade girl, hand on hip, expressed the class' growing exasperation with the slow witted mathematics professor who couldn't understand the obvious.

Dr. Diane Briars, Director of Mathematics, invited me to discuss modern mathematics with the teachers and several student groups as part of the Pittsburgh Public Schools' observance of the national "Mathematics Awareness Week." It was easy to prepare for classes from the eighth grade on - a grab bag of unexpected examples from "chaos," mathematical astronomy, properties of surfaces, and statistical paradoxes could illustrate mathematical themes while capturing their imagination. But I fought to disguise my growing panic when informed that I was to talk to a fourth grade class. What does one say to fourth graders? It didn't help to discover on arrival at the East Hill's Elementary School that the core of my intended audience, Ms. Chamberlain's class of very young children, all were sufficiently short to inspire extreme caution while walking about.

I have found that the mathematics of decision making - in particular, voting - serves as a useful vehicle to introduce a variety of mathematical concepts starting with elementary counting, to algebra and geometry, and then, on a research level, certain delicate mathematical symmetries. So, I figured I could survive my allotted forty minutes by describing a counting problem caused by a voting example.

The posed problem involved an hypothetical group of fifteen children permitted to watch only one TV show for the evening. Of these children,

\begin{tabular}{|lccc|}
\hline & Best & Second best & Last \\
6 preferred & Alf & Flash & Bill Cosby \\
5 preferred & Bill Cosby & Flash & Alf \\
4 preferred & Flash & Bill Cosby & Alf \\
\hline
\end{tabular}

Which show should they watch?

With sophistication gained through years of voting we know the answer is "Alf" because the election outcome is

Alf is preferred to Bill Cosby is preferred to Flash

My visit to Pittsburgh was supported, in part, by an NSF grant to the University of Pittsburgh. The recent research results described in this article were supported by NSF Grant IRI-8803505. 
with a vote of $6: 5: 4$. My worse fears were realized when immediately after posing the problem the class answered in unison, with that droning sound of a class participating in a drill of addition facts, "Flash." Were these students too young to understand the simple relationship between counting and voting? If, instead, they were expressing personal favorites, then I would need to brace myself for a dreadfully long forty minutes.

Calling on any poise hopefully gained through years of motivating college students, I challenged their conclusion. Their instant response, "Well, you see, to choose the best show you have to count the number of times each show is in first place and how many times the kids like it next best." "If you look, some kids like Flash the best and all other kids like Flash next best, but all other shows many kids like the worst." Maybe they did understand.

I persuaded them to indulge in my suggestion ("Let's count how many people like each show the best!") of using the standard election procedure. While tending to treat my suggestion as a silly aside, they politely agreed that it would define the ranking

Alf is preferred to Bill Cosby is preferred to Flash.

Then I complicated the story with the announcement, "Alf is canceled tonight, now what should these kids watch?" With our voting experience, this is a simple problem; choose the second choice show Bill Cosby. Their immediate response, again with a frightening unison, "Flash!"

After I challenged this second answer, even more children entered the debate by countering "You just can't count who likes what show the best, you have to see what they like next best too." "Your counting way that makes Alf best and Bill Cosby next best is silly." "Count! If you count you'll see more kids like Flash than Bill Cosby." They are correct; in this example the last-place Flash defeats second-place Bill Cosby by 10 to 5. Then, before I could use my punch lines that "last place Flash is preferred even to first place Alf" and "more people prefer second place Bill Cosby to first place Alf," most of the children proved they had completed the analysis by triumphantly calling out "Look, count! See, they like

Flash best, Bill Cosby next, and Alf last!"

"We tried to tell you, these kids like 'Flash' best!" It was when I stood silently, astonished by their insight and quickness rather than the conclusions of my concocted election example, that I got my reprimand. More were to follow.

This example illustrates just one of many serious flaws attached to our standard tool of democracy; it is not unusual to find that the winner of our standard plurality election outcome is, in fact, the candidate viewed as being inferior by these voters - while the candidate the voters view as superior ends up losing. Actual elections exhibiting this behavior are not difficult to find. The flaw does not reside in the voters' preferences; it is an artifact of the chosen voting method. So, it isn't surprising to learn that the search for "better" election procedures has been a serious political concern throughout the centuries. For example, almost a millennium ago the standard process of choosing the simple majority winner caused strife and even violence within the Catholic Church leading to competing claims of who is the "real Pope." These conflicts ceased after the design and adoption in 1179 of the selection process still in use. (Anyone is eligible to be elected Pope; all you need is to receive one more than $\frac{2}{3}$ of the votes cast by the Cardinals.)

The modern study of elections was initiated by the French mathematician J. C. Borda in his presentation to the French Royal Societe in 1771. He, along with fellow academy 
members such as Condorcet and Laplace, recognized that while it appears to be simple to choose an election procedure, it is not; it is mathematically quite complicated. Indeed, since the 1780's, this topic has received the attention of hundreds of researchers writing thousands upon thousands of published papers, yet much of the mystery remains untouched.

What is the "correct" procedure? Such a question is unfair to ask of any audience, even professionals. So, more out of curiosity than with any expectation of a response, I tried it on my fourth grade subjects. "How should these children choose the TV show to watch?" Quietly but surely Cara answered, "Well, I think we should give 3 points to the show we like the very best and 2 points to the show we like next and only 1 point to the show we like the last. This way we can also tell what other shows the kids like other than their best one." This is Borda's procedure; a process that only recently has been shown [S1] to be optimal for many reasons. Abe, an obviously bright boy who knew it, countered with "I want to give 1 point to our best show and 0 points to our next show and -1 points to our last show." A fourth grader advancing a procedure based on a negative number of points! ${ }^{1}$ Then Susan suggested, "How about giving 2 points to our best show and 1 point to the next show and no points for the last show." By now everyone wanted their say, but several children cut off further discussion by pointing out that each of these procedures must yield the same election outcome.

They were, as usual, correct. As they argued, it doesn't matter how many points are assigned to each candidate; the critical factor is the point spread between the first and second ranked candidates, and the second and third ranked candidates. The differential for each of the three proposed methods is a single point, so the election rankings must remain the same. In fact, by using any of the Borda - Cara - Abe - Susan procedures with the above example the election ranking is

Flash in first place, Bill Cosby is in second place, and Alf in last

- an election ranking that completely reverses the plurality outcome and that is totally consistent with the pairwise rankings of the TV shows. Using Cara's 3-2-1 method, the tally sheet is

\begin{tabular}{|cccc|}
\hline Voters & Alf & Bill Cosby & Flash \\
6 & 18 & 6 & 12 \\
5 & 5 & 15 & 10 \\
4 & $\underline{4}$ & $\underline{8}$ & $\underline{12}$ \\
Total & 27 & 29 & 34 \\
\hline
\end{tabular}

Incidentally, only recently has it been discovered [S2] that the Borda Method is the sole procedure where its election outcomes must exhibit this kind of consistency. Namely, for any other way to tally the ballots where the differential between points is not a constant, there need not be any relationship among the election rankings of the candidates and the pairs of candidates! As an extreme illustration, choose rankings for each pair of candidates in an arbitrary fashion (say, by flipping a coin) and choose an arbitrary ranking of the three candidates (say, by consulting a lotto outcome). The disturbing fact is that an example can be created (maybe requiring more than 15 voters) where each voter has a specified ranking of the candidates and where the actual election ranking for each set of candidates

\footnotetext{
${ }^{1}$ When I questioned how many could operate with negative numbers, over half of the class responded with confidence.
} 
is the arbitrarily selected one! ${ }^{2}$ This does not inspire confidence in the outcomes of these widely used instruments of democracy. Only the Borda method provides immunity from all possible kinds of electoral chaos.

Back in the fourth grade classroom, I still had twenty minutes to go! So, I started constructing a version of a puzzling example advanced in the 1780's by Condorcet which he designed, most surely, to respond to Borda's method; an example that continues to motivate the voting and decision literature. After writing down

$\begin{array}{lccc} & \text { Best } & \text { Second best } & \text { Last } \\ 5 \text { preferred } & \text { Alf } & \text { Bill Cosby } & \text { Flash } \\ 5 \text { preferred } & \text { Bill Cosby } & \text { Flash } & \text { Alf }\end{array}$

a girl in the front volunteered, "And you are going to say next that 5 like Flash best, Alf next, and Bill Cosby last." She was correct. A version of the Condorcet example has

\begin{tabular}{|lccc|}
\hline & Best & Second best & Last \\
5 preferred & Alf & Bill Cosby & Flash \\
5 preferred & Bill Cosby & Flash & Alf \\
5 preferred & Flash & Alf & Bill Cosby \\
\hline
\end{tabular}

A simple count shows that by 10 to 5 these people prefer Alf to Bill Cosby and by the same 10 to 5 they like Bill Cosby over Flash. Presumably, they prefer Alf to Flash, so Alf is the top-choice. Yet, when asked which show these kids prefer, again the class answered in unison but now very far from monotone, "Nobody is best; they are all the same." A patient student, in a patronizing fashion, explained slowly to me, "See. Each show is the same number of times in top place and in second place and in last place. That is why there is no favorite; they're all the same."

Sticking to my guns, I insisted on comparing Alf with Bill Cosby to demonstrate the 10 to 5 conclusion; an assertion greeted by an avalanche of outbursts, "Yes, and Bill Cosby will be better than Flash and Flash will be better than Alf by the same numbers." They were correct; the purpose of Condorcet's example is to illustrate that cycles - even of landslide proportions - can arise when we retreat to our comfortable procedure of using the majority vote with pairs. One incredibly small boy took pity on me by carefully offering, "Let me explain. Nobody is better; they are all the same. It's like the rock and the sizzors and the paper. The rock can dull the sizzors and the sizzors can cut the paper and the paper can cover the rock, so nothing is better than the others." He was correct, of course. They are the same.

To fill the remaining few minutes, I posed a (recently solved) research problem, offered a dollar reward for each solution, and was relieved when my wallet was saved by the class bell.

\footnotetext{
${ }^{2}$ This defines a nice set of exercises for an algebra class familiar with several variables. Choose any method to tally ballots that is not Borda; e.g., the plurality method where one point is given to the top ranked candidate and zero for all others, or a method where 5 points are given to a top ranked candidate, 2 to a second ranked candidate, and zero to the last. Now, there are only six ways the candidates can be listed, so if the number of voters with each ranking is an unknown, we have six unknowns. The specified election outcome for each of the four subsets of candidates leads to five inequalities with six variables. Any solution provides an example.
} 
These are not obvious issues - versions of them have confused generations of professionals from mathematics, economics, political science, and many other research areas; but not these fourth graders! With innocence coupled with awakened curiosity, with insight freed from our myopic view blurred by years of blind acceptance of our standard but flawed election procedure, these fourth graders cut through the conceptual difficulties to achieve critical understanding. In other words, the pressures of the playground and group interactions have formed a sense of fairness within these children, but a sense that has yet to be codified (i.e., restricted) through an unquestioning adoption of accepted methods. Rather than relying upon a mechanical conclusion (as we usually do), they found reasonable answers by examining the data.

But there is another issue here. If this class is an indication of what is possible at such a young age, then we must wonder what it is we do to destroy the natural creativity and inventiveness exhibited by these children. We must wonder how our usual classroom approach of imposing solutions through authority rather than exploring ideas to generate and understand answers can lead us to mediocrity. In other words, we must wonder what can we do to be part of the solution, rather than the problem.

Out of fairness, about a third of these children participated in Dr. Briars' experimental program to enrich the standard mathematics curriculum. ${ }^{3}$ Rather than teaching ahead, the goal is to build self-confidence and creativity by encouraging exploration, awareness, and risk-taking through an expanded use of familiar grade-level mathematics. One measure of the inventiveness gained by the students through their "problem solving" sessions, taught and designed by Rick Wertheimer, is that prior to my lecture they had seen nothing even resembling these voting examples. I hope they will in the future. I also hope that other professional mathematicians will volunteer to lecture at a local school system. Try it, armed with a sense of humor, you'll like it. And, if a fourth grade class is scheduled, be sure to bring along an unsolved research project.

\section{REFERENCES}

S1. Saari, D. G., "The Borda dictionary," Social Choice and Welfare 7 (1990), 279-317.

S2. Saari, D. G., "Dictionary for voting paradoxes," Jour. Economic Theory, 48 (1989), $443-475$.

Department of Mathematics, Northwestern University, Evanston, Illinois 60208-2730

E-mail address: d_saari@math.nwu.edu

\footnotetext{
${ }^{3}$ This class does not constitute an isolated case. Based on a draft of this essay, some teachers and parents have tried the same experiment (even with a second grader!) and found, for the most part, the same kinds of reactions.
} 